\title{
Observing "Myself” in the Video: Fostering Reflective Practice in Oral Presentation Training
}

\author{
Aiping Li*, Tianxiao Peng \\ School of Arts and Sciences, National University of Defense Technology, China \\ Corresponding Author: Aiping Li, E-mail: liaiping08@nudt.edu.cn \\ The research is financed by the Hunan Educational Science Fund, China. No. XJK015BGD001.
}

\begin{tabular}{l} 
ARTICLE INFO \\
\hline Article history \\
Received: March 08, 2018 \\
Accepted: May 01, 2018 \\
Published: June 30, 2018 \\
Volume: 9 Issue: 3 \\
Advance access: May 2018 \\
\hline
\end{tabular}

Conflicts of interest: None

Funding: Hunan Educational Science

Fund, China. No. XJK015BGD001.

\begin{abstract}
This paper proposes using video-supported reflection to facilitate EFL students' reflective practice of oral presentations. Based on reflective learning theory, four teaching stages are designed and used in an intensive oral presentation training project: creating reflection scenarios, providing reflection scaffolds, guiding collaborative reflection, and summarizing learning gains. Data are collected through students' reflective journals and focus group interviews. Findings indicate that the project has a positive impact on students' reflective abilities and their perceived learning gains. Problems encountered by the students are identified and discussed in light of research and practice on how to support and enhance reflective learning.
\end{abstract}

Key words:

Reflective Learning,

Reflective Journals,

Video-supported Reflection,

Reflective Thinking Levels,

Oral Presentation

\section{INTRODUCTION}

As an essential professional communication skill for employees of the $21^{\text {st }}$ century, oral presentation (OP) is strongly recommended by English as Foreign Language (EFL) educators for classroom teaching. Often, because of time constraints, students are given little or no opportunities to practice oral presentation, and they are "obliged to do much of the work on their own"(Boyle 1996:117). In EFL teaching practice, most students are simply assigned to do this task as an assessment, but seldom get adequate feedback from the teacher.

How can we improve this situation? Researchers have emphasized that the teaching of communication skills should value the necessity of involving students in purposeful reflection on their own weaknesses. At the same time, video reflection has been embraced across a range of discipline areas, such as language education, preservice teacher training and medical education, etc. Despite the acceptance of reflection or video reflection in education, Ryan (2013) states that learners are not often taught how to reflect or how best to communicate their knowledge through reflection. A review of the related literature shows that there has been a lack of empirical study on the impact of video-supported reflection on students' reflective practice in English language teaching. Thus there is still much to be understood regarding how video-supported reflective practice gets done to facilitate students' reflective practice of oral presentations.

Drawing on the theory of reflective learning, this study attempted to incorporate a video-based reflective learning project into an intensive OP training program in the EFL course at tertiary level. The study aimed to describe how the target students could be guided to get involved in reflective practice, and examine how the project would affect students' reflection ability and evaluations of the learning experience. We attempted to contribute further concrete evidence to substantiate the benefits of using video-supported reflective learning in oral presentation training. It was designed around the following research questions:

1) Does video-based reflective learning help students to enhance the breadth and depth of their reflection on oral presentation performance?

2) What are students' feedback and evaluation of the video-based reflective learning project?

\section{THEORETICAL BACKGROUND}

\section{Reflection and Reflective Learning}

Reflection is generally viewed as a systematic, cautious and well-trained cognitive process. According to Boud, Keogh 
and Walker (1985), reflection is a 'highly context-specific' process in which constructing appropriate process, creating supportive environment and establishing reciprocal communication play a key role for deep reflection. Rodgers (2002) puts forward the concept of "reflection in problem-solving" which involves rethinking and reconsideration of past events and experiences with an intention to obtain better solutions.

In the $21^{\text {st }}$ century, high value is placed on reflective learning and developing reflective learners. However, reflection is difficult for both students and practitioners. Our commonly perceived barriers of reflective learning include: lack of time, reflection undervalued by teachers, students' lack of reflection awareness and under-developed reflective ability, limited experience of using reflection tools, fear of failure, and lack of feedback. Therefore, reflective scaffolds such as the reflective cycles, tools, and activities have become essential to create a supportive and safe environment conducive to deep reflection.

\section{The Reflective Cycle}

Reflective learning is a dynamic and cyclical process in which experience and reflection on experience are interrelated. A number of reflective cycles or models have been developed in the literature. Gibbs' (1988) question-led reflective cycle is one of the most widely used models. It aims to guide learners to achieve deep reflection through six interlocking steps and six corresponding questions as follows:

- description (what happened?);

- feelings (what were you thinking and feeling?);

- evaluation (what was good and bad about the experience?);

- $\quad$ analysis (what sense can you make of the situation?);

- conclusion (what else could you have done?); and

- $\quad$ action plans (if it rose again, what would you do with it?). Gibbs' model acknowledges the importance of reflective practitioners' personal feelings in reflection, provides a straight-forward point of analysis for them to look at their learning experiences from a number of perspectives, and to take actions in handling their problems in the future. For the purpose of this study, we decided to use Gibbs' reflective cycle to guide students to achieve deep reflection.

\section{Data-led and Tool-supported Reflection}

Walsh and Mann (2015) state that more emphasis is needed on using data-led and tool-supported reflection to scaffold reflective learning. Reflection data, such as reflective journals can help learners externalize their thoughts on learning, making reflection more concrete, and learners can see how reflection gets done in practice. Keeping reflective journals contributes positively to effective acquisition of learners' discipline knowledge and critical problem solving skills. Another benefit of keeping reflective journals is that they can be served as evidence of reflective thinking and used to diagnose deficiencies of students' abilities to think reflectively and critically (Kember, Jones, Loke, \& McKay, 1999).

Reflective tools, like videos, might act as evidence for learners' reflection. Videos can capture the complexity and authenticity of students' learning performance and be viewed many times to do precise observation and deep analysis. Videos can also be shared and discussed in the groups. This kind of collaborative video reflection is helpful, especially for our oral presentation project, because students can get a closer inspection of their partners' performance, analyze it from different perspectives, and learn new approaches or strategies to solve others' and their own problems. Some studies have reported the effectiveness of video reflection in teacher education, such as helping learners pay more attention to the details and inspire deeper reflection (Rosaen, Lundeberg, Cooper, Fritzen, \& Terpstra, 2008) and improving interactive learning and speaking skills (Moore \& Voth 1997).

\section{Measures of Reflective Thinking}

To assess the quality of learners' reflective thinking, researchers have developed several schemes, such as grading different levels of reflective thinking through questionnaires and analyzing students' written reflective journals. Lee's (2005) measurement focuses on analyzing the reflective entries learners make, and assesses them from two perspectives: content and depth. The content refers to the breadth of the reflective thoughts, namely the main concerns of the students, and the depth contains three hierarchical levels of recall, rationalization and reflectivity, which could be characterized as follows:

- $\quad$ recall is the description of what one experiences and a response to "what did I do?";

- rationalization refers to looking for relationship between different experiences, trying to explain the learning situation and answer "what is the impact?" or "why things happened like this?" and;

- reflectivity approaches the experiences with an aim to answer "what should I do" to solve the problems.

Lee's reflective thinking evaluation framework has been employed by a lot of educators (see Cheng \& Chau, 2013). It was employed by this study to examine what content and what levels of reflection our target students would engage in the video-based reflective practice.

\section{THE STUDY}

\section{Context and Participants}

The study was conducted in an English Course taught by the first author at a Chinese University. Participants were 30 first year students. Oral presentation is a regular activity for the course. Before the study, they all had experience of making English oral presentations but no previous experience in video-based reflection on their oral presentations.

\section{Intervention}

The study took place over a period of seven weeks. A systematic, structured and student-centered reflective learning project was constructed and carried out to foster students' reflective practice through four main stages. 
Stage 1: Creating reflective learning scenarios

In the first week, an orientation session which included the purpose of the project and the dos and don'ts was offered to the 30 students. Then, in Week 2 and Week 3, each student made a PowerPoint-aided oral presentation introducing their selected reading material in class, and answered the audience's questions. Their performance was videotaped. After the students finished the presentations, they were required to write a reflective journal to comment on their performance without watching their videos.

Stage 2: Scaffolding self-reflection

In Week 4, the students watched three OP samples videos, with one representing the excellent level, one the average, and another one the poor level. To clarify the evaluation criteria, we developed an oral presentation evaluation checklist which covers four major items including organization, content, delivery skills and question response, along with a total of 12 sub-items, as given in the Appendix. The students assessed the videos by filling out the evaluation checklist. In Week 5, the students watched their own videos and reflected on their performance by referring to the evaluation checklist and answering Gibbs' six reflection questions.

Stage 3: Guiding collaborative reflection for alternative solutions

In week 6 , the students worked in free-formed groups to watch their videos and discuss their strengths, weaknesses and solutions from multiple perspectives. The teacher walked among students to provide instant answers to their questions, and for some typical controversial questions, the teacher discussed with the whole class. During the discussion session, a friendly, trustful and effective cooperative learning atmosphere was created, and the effective interaction between the teacher and students provided timely and rich learning feed-backs, which guaranteed that students would not stuck in confusion or frustration, and that they eventually find solutions to the problems.

Stage 4: Summarizing reflection experience

In Week 7, each student wrote a reflective journal to reflect on their oral presentation again. To avoid language barriers, they were allowed to choose both Chinese or English to write their reflective journals. At the end of this project, three focus group interviews were conducted to examine the students' evaluations of the project.

\section{Data Collection and Analysis}

\section{Students' reflective journals}

A total of 60 students' reflective journals written both before and after video observation were collected and analyzed using content analysis. Each reflective journal was analyzed through two stages of analysis. In the first stage, we focused on the breadth of students' reflective entries, namely what specific aspects they mentioned about their oral presentation performance. All the reflective entries were read several times until some categories of themes emerged and were categorized into several main categories, and these were refined later and their corresponding subcategories were identified. Altogether, 4 main categories and 14 subcategories were extracted (see Table 1). We coded each reflective journal independently, and calculated the frequency of each reflective entry the students made.

The second stage of content analysis consisted of exploring the depth of students' reflective thinking. We examined the reflective entries in each subcategory and rated them using Lee's (2005) evaluation framework of reflective thinking and calculated the frequency of reflection in the three levels. For convenience of analysis, we assigned a score to the three reflection levels $(1=$ recall, $2=$ rationalization, and $3=$ reflectivity). Examples of the reflective entries and its coding are shown below:

- "I appeared to be relaxed and confident": Level 1

- "My presentation lacked visual aids. That made my audience bored and puzzled": Level 2

- 'I noticed that I said 'um' too often. Annoying! How can I get rid of this? My partners told me that I did it while I was not sure about what to say next. A good way to kick it is to do a lot of practice because the more familiar I am with my speech, the less chances for me to repeat it. I tried it later and improved a lot": Level 3.

To ensure the reliability of data analysis, any disagreements on the two coders' coding decisions were discussed until an unanimous agreement was reached.

\section{Focus group interview}

Following the completion of the study, three focus group interviews were conducted, each with 10 participants. Each focus group interview was conducted according to established principles (Morgan, 1997). The participants were invited to answer and discuss questions relating to the following themes: participants' general perceptions on the project, their major gains, and the difficulties or challenges they encountered in this project.

\section{RESULTS}

\section{The Breath of the Students' Reflective Thinking}

The result shows that after browsing videos of their oral presentations, the students were able to discern more behavioral characteristics of their performance (see Table 2). In sum, there was a significant increase in the total number of students' reflective entries. The number of 30 students' reflective entries increased from 128 before video observation to 311 after video observation. From the distribution of reflective notes, before video observation, students' concerns focused on psychology and attitude (29 notes, $22.7 \%$ ), topic choice ( 24 notes, $18.8 \%$ ) and content richness (13 notes, $10.0 \%$ ), with less concerns on accuracy, body gestures and other details. After video observation, the number of reflective notes students made in the general aspects of psychology and attitude, topic choice and content richness decreased by 6,5 and 2 respectively. In addition, they made considerable more reflective notes on the more specific aspects, such as the introduction, conclusion, language accuracy, voice effect, eye contact, body gestures, multimedia aids, and question-answer strategies, 
Table 1. Coding categories of the content of students' reflective entries

\begin{tabular}{ll}
\hline Main categories & \multicolumn{1}{c}{ Sub-categories } \\
\hline Structure & (1a) introduction, (1b) body, (1c) conclusion \\
Content & (2a) topic choice, (2b) accuracy, (2c) logic, (2d) richness \\
Delivery & (3a) psychology \& attitude, (3b) style, (3c) voice effect, (3d)eye contact, (3e) body gestures, (3f) multimedia aids \\
Question response & (4a) question-answer strategies \\
\hline
\end{tabular}

Table 2. Frequency distribution of students' reflective entries before and after video observation

\begin{tabular}{|c|c|c|c|c|}
\hline Category & Subcategory & $\begin{array}{l}\text { Before video observation } \\
\text { count (percentage) }\end{array}$ & $\begin{array}{l}\text { After video observation } \\
\text { count (percentage) }\end{array}$ & Increase \\
\hline \multirow[t]{3}{*}{ Structure } & Introduction & $7(5.5)$ & $30(10.0)$ & 23 \\
\hline & Body & $0(0.0)$ & $9(3.0)$ & 9 \\
\hline & Conclusion & $6(4.7)$ & $24(8.0)$ & 18 \\
\hline \multirow[t]{4}{*}{ Content } & Topic choice & $24(18.8)$ & $19(6.3)$ & -5 \\
\hline & Accuracy & $6(4.7)$ & $29(9.6)$ & 23 \\
\hline & Logic & $2(1.5)$ & $14(4.7)$ & 12 \\
\hline & Richness & $13(10.0)$ & $11(3.7)$ & -2 \\
\hline \multirow[t]{6}{*}{ Delivery } & Psychology \& attitude & $29(22.7)$ & $23(7.6)$ & -6 \\
\hline & Style & $7(5.5)$ & $16(5.3)$ & 9 \\
\hline & Voice effect & $14(11)$ & $29(9.6)$ & 15 \\
\hline & Eye contact & $4(3.1)$ & $26(8.6)$ & 22 \\
\hline & Body gestures & $6(4.7)$ & $19(6.3)$ & 13 \\
\hline & Multimedia aids & $10(7.8)$ & $27(9.0)$ & 17 \\
\hline Question response & Question-answer strategies & $0(0.0)$ & $25(8.3)$ & 25 \\
\hline Overall & & $128(100)$ & $301(100)$ & 173 \\
\hline
\end{tabular}

with a growth number of $23,18,23,15,22,13,17$ and 25 respectively.

\section{The Depth of Students' Reflective Thinking}

Overall, students produced deeper and more meaningful reflective notes after video reflection (See Table 3). Before video observation, only $13.3 \%$ of their reflective notes scored 3, the highest level of reflection. The students' reflective journals were mainly composed of notes scoring 1 (79 notes, 61.7\%) and 2 (32 notes, 25.0\%). After video observation, the students' reflective notes scoring 2 and 3 increased to $69(30.9 \%)$ and $196(65.1 \%)$, with a percentage increase of $115.6 \%$ and $1052.9 \%$ respectively. On the other hand, the percentage of the students' reflective notes scoring 1 dropped dramatically to $36(12 \%)$, with a percentage decrease of $54.4 \%$.

\section{Students' Evaluations of the Project}

\section{General perceptions}

The overwhelming majority of students $(86.7 \%)$ thought that the video- based reflective learning was an interesting, dynamic and flexible way of gaining knowledge and developing skills. Unlike traditional teacher-centered lecturing, it placed the students at the centre of their own learning and pushed them to take the responsibility and autonomy to learn and develop themselves. Sample quotations illustrating the findings are:

It's one of the most motivational, supportive and meaningful experience. it made us find a purpose to learn and take the ownership of learning.

The most striking advantage of this project is that it can give us a sense of effective and deep learning, which I think is the biggest distinction between active learning and listening to the teachers silently and apathetically.

\section{Learning gains}

Students reported various gains ranging from improved knowledge, skills and self-efficacy. Regarding the knowledge gains, the majority reported that they improved English language knowledge (60\%), such as pronunciation, vocabulary and grammar; some said they got deeper understanding of the oral presentation topics $(56.6 \%)$, while a very large proportion of students believed that they improved knowledge of oral presentation strategies $(83.3 \%)$. As one student put it:

The biggest gain is the strategies to make an effective oral presentation. You'll never notice there are a lot of things you need to improve until you see yourself and others from the videos. Now I know that only with a little focus and a little improvement of techniques, I can do much better.

Skill development is the key learning gain of students, with $86.7 \%$ of them reporting their improved reflective 
Table 3. Distribution of the students' reflection levels before and after video observation

\begin{tabular}{lccc}
\hline Reflection levels & $\begin{array}{c}\text { Before video observation Count } \\
\text { (percentage) }\end{array}$ & $\begin{array}{c}\text { After video observation Count } \\
\text { (percentage) }\end{array}$ & Percentage increase \\
\hline 1 & $79(61.7)$ & $36(12.0)$ & -54.4 \\
2 & $32(25.0)$ & $69(22.9)$ & 115.6 \\
3 & $17(13.3)$ & $196(65.1)$ & 1052.9 \\
Overall & $128(100)$ & $301(100)$ & 135.2 \\
\hline
\end{tabular}

Level 1=recall; Level 2=rationalization; Level 3=reflectivity

skills, $76.7 \%$ evaluation skills and $66.7 \%$ oral presentation skills. Further discussion during the focus group interview suggested that this project is really skill-centered. They reported:

This kind learning surpassed 'the acquisition of mere knowledge', with a core aim to teach us how to reflect. I will use the reflective skills I've grasped in other subjects, especially in my mathematics modeling experiments.

I learned how to evaluate oral presentations. Also, I am able to be open to my partners' comments and know how to give constructive suggestions to them skillfully. That is, before pointing out their mistakes, make sure you say 'I admire your way of., or I like your style of.' That can make everyone happy.

Another big gain was the internal self-efficacy. Over $86 \%$ of the students found that with better mastery of the knowledge and skills, they were more confident to make oral presentations. A total of $63.3 \%$ of the students perceived themselves as being more experienced. Some students also thought they could "work and think like an experienced presenter and reflective learner".

\section{Encountered concerns or difficulties}

In order to inform future deployments, this study investigated the concerns or difficulties the students experienced in the project. What caused the biggest difficulty was having to film the oral presentation because that would take a lot of preparation time and lead to nervousness about self-image. Several students stated the camera is a huge source of anxiety. Another challenge mentioned was the inexperience of refection. They thought that they were not good reflective learners, and could not recognize a weakness quickly. Few students mentioned the difficulty to understand or accept the evaluations from their partners and to work with the partners who are passive or silent in discussion.

\section{DISCUSSION}

The aim of this study was to guide and analyse students' reflective learning processes, to unfold how their reflective skills change, and to examine their evaluation of the project. Findings from reflective journals show that to a large extent the video-supported reflective learning project has improved the breadth and depth of students' reflection. The focus group interviews indicate students' positive feedback on this project despite some problems encountered. There are several specific characteristics of the pedagogic design of the study that have supported students' reflective learning processes, and there are also some solutions to solve the encountered problems.

\section{Videos as a Source of Evidence and Motivation to Change}

One reason why students have generated more specific reflective notes is the use of video. Reflective learning should be supported by rich learning scenarios. Video observation can offer evidences and means for the students to correct their mistakes. Students in this study noted that when observing themselves in the video they were surprised by more specific behaviors, resulting in an increased number of reflective notes and an increased desire to improve their performance. This is similar to the research of Tripp and Rich (2012) that after a video reflection process reflective practitioners had a stronger motivation to change and improve their practice along with an enhanced understanding about how to change. Video reflection promotes students' self-discovery and self-appropriated learning, with which behavior change is more likely to happen.

\section{Group Collaboration for Deep Reflection}

Aside from the student videos, group collaboration has provided a unique forum for the students to exchange the problems and solutions. Group viewing of peer oral presentation episodes could add dynamic to the traditional lecture-based teaching which tends to suppress reflection because of its didactic style of teaching. In the collaborative reflection process, all group members serve as both the students and the critics. In our study, collaborative reflection is especially useful for the majority of intermediate-level participants. They appreciated the activity of group interaction, because it offered a supportive environment which helped minimize their feeling of 'loneliness and helplessness' in learning, and facilitated deep reflection. Through the give and take with others and by confronting the challenges, critical reflection is therefore promoted.

\section{Teacher's Guidance as Scaffolds to Transformative Reflection}

To promote students' engagement, this study provided appropriate reflective guidance from a reflective process dimension and a reflective environment dimension. The reflection process was triggered by different activities, especially the oral presentation evaluation, the question-guided 
individual reflection, collaborative reflection and reflective journal writing tasks. A supportive reflective environment which aimed to inspire the students' positive attitudes and learning responsibilities was created through the orientation session of the project and the instruction of collaborative reflection and reflective journal writing tasks.

Reflective learning practice will not have much effect if teachers do not establish a clear reflective frame and structured reflective procedure. In the interview, most students reported that they had little prior reflective learning experience and did not know how to reflect. In this project, the four stages of creating reflective situations, providing reflective support, guiding reflective interaction and summarizing reflection experience effectively guided them to complete the whole process of reflection. They also expressed their preference for a programmatic way of reflection, because it helped them catch the point without losing their way. The teachers' scaffolds provided a structure that made their in-depth reflective thinking "possible and enjoyable", helped them develop an awareness to methodically combine learning and self-reflection, and enabled them to improve their reflection ability, to challenge and surpass themselves. We would argue that the goal of teacher's scaffolding is to arrive at what Ryan calls a 'transformative reflection' (Ryan 2013: 146). When reflective processes move to transformative or intensive levels, critical reflection and sustainable learning practices are guaranteed.

\section{Adjusting Reflective Learning with a Reflective Approach}

Finally, it should be noted that while this study is effective in facilitating students' reflective practice, there are some problems to be dealt with. In our study, students remarked the problems of learning anxieties, self-doubts and inexperience of reflection. This may have been a result of the fact that the students were relative novices in reflective learning, especially in the video-based reflective learning scenario. Reflective learning as a complex cognitive activity is never an easy task. To solve these, teachers need to adjust their instruction with a reflective approach. Several measures could be taken in implementing the video-based reflective learning project.

To deal with the problems of nervousness, self-doubt and distrust of other' opinions, teachers should first accept the fact that it is natural for novice learners to have these feelings. Teachers are supposed to make it clear to learners that a certain degree of self-doubt is good for reflective learning, because it is only when practitioners inquire into their own practice from a position of uncertainty and doubt that reflection really occurs. At the same time, teachers should create a safer environment for them to practice more, encourage them to express themselves intellectually and emotionally, and guide them to grow from self-doubt to increased self-confidence and towards self-fulfillment.

If certain learners have limited experience or ability of reflection, teachers may get them involved in a series of structured activities and allow more time for them to practice. The teacher may give a real-time demonstration of how to reflect for learners' reference, guide them step by step until they can finish the whole task on their own.
To enhance the efficiency of reflective learning, teachers must avoid the instruction of "recipe following" (Boud and Walker 1998: 193), which just aims to push students to work through the reflective activities in a mechanical way without taking account of the uniqueness of the students, the specific learning context and the uncertainties or questions they may encounter in learning. Reflection might take on a variety of forms or processes, dependent on a wide range of factors, that teachers should take a contextualized view of reflection. This requires teachers to focus on the learners' uniqueness and the social cultural context in which reflection takes place. In future work, we intend to offer a kind of flexible menu-style learning activities to meet different students' needs, permitting them to choose freely and make meaning actively to optimize the learning results.

\section{CONCLUSION}

This study is a response to the current call for teaching students how to reflect in deep, critical and transformative ways, and for doing reflective practice in a data-led and tool-supported way. It offered empirical evidence for the effectiveness of the video-based reflective learning. Findings showed that a video-based reflective learning project could improve both the breath and depth of the students' reflective entries, and result in their positive evaluations on the project. Moreover, this study identified some difficulties emerging among the participants and proposed to adjust them with a reflective approach.

Although situated within an EFL curriculum and with findings that should be interpreted with caution in different contexts, this study has added to our relatively limited knowledge of how reflective practice "gets done" in the EFL teaching context, which may contribute a possible solution for teachers to improve oral presentation training and foster reflective learning. The ultimate goal for a video facilitated reflection activity is for the learners to act on the feedback to result in some improvements in behavior. Future studies should follow participants over longer practice and collect data to examine the development of their oral presentation skills.

\section{REFERENCES}

Boud, D., \& Walker, D. (1998). Promoting reflection in professional courses: The challenge of context. Studies in Higher Education, 23, 191-206. http://dx.doi.org/10.10 80/03075079812331380384

Boyle, R. (1996). Modelling oral presentations. ELT Journal, 50(2), 115-126. http://dx.doi.org/10.1093/elt/50.2.115

Cheng, G. \& Chau, J. (2013). A study of the effects of goal orientation on the reflective ability of electronic portfolio users. Internet and Higher Education, 16, 51-56. http://dx.doi.org/10.1016/j.iheduc.2012.01.003

Gibbs, G. (1988). The reflective cycle. Oxford: Further Education Unit, Oxford Polytechnic.

Kember, D., Jones, A., Loke, A., \& McKay, J. (1999). Determining the level of reflective thinking from students' written journals using a coding scheme 
based on the work of Mezirow. International Journal of Lifelong Education, 18(1), 18-30. http://dx.doi. org/10.1080/026013799293928

Lee, H. (2005). Understanding and assessing preservice teachers' reflective thinking. Teaching and Teacher Education, 21, 699-715. http://dx.doi.org/10.1016/j.tate.2005.05.007

Mann, K., Gordon, J. and MacLeod, A. (2009). Reflection and reflective practice in health professions education: A systematic review. Advances in Health Sciences Education, 14(4), 595-621. http://dx.doi.org/10.1007/ s10459-007-9090-2

Moore, M. \& Voth, B. (1997). The pedagogical values of video portfolios in basic public speaking courses. Journal on Excellence in College Teaching, 8(2), 87-105.

Morgan D. (1997). Focus groups as qualitative research. Thousand Oaks: Sage.
Rogers, C. (2002). Defining reflection: Another look at John Dewey and reflective thinking. Teachers College Record, 104, 842-866. http://dx.doi.org/10.1111/14679620.00181

Ryan, M. (2013). The pedagogical balancing act: Teaching reflection in higher education. Teaching in Higher Education, 18(2), 144-155. http://dx.doi.org/10.1080/13562 517.2012 .694104

Tripp T., \& Rich, P. (2012). Using video to analyze one's own teaching. British Journal of Educational Technology, 43, 678-704. http://dx.doi.org/10.1111/j.14678535.2011.01234.x

Walsh, S., \& Mann, S. (2015). Doing reflective practice: a data-led way forward. ELT Journal, 69(4), 351-362. http://dx.doi.org/10.1093/elt/ccv018

\section{APPENDIX}

\section{Appendix: Oral presentation evaluation checklist}

\begin{tabular}{|c|c|c|c|}
\hline \multicolumn{4}{|l|}{ Structure } \\
\hline Clear introduction & _Body & _Strong conclusion & \\
\hline \multicolumn{4}{|l|}{ Content } \\
\hline _Topic choice & _Accuracy & _Logic & _Richness \\
\hline \multicolumn{4}{|l|}{ Delivery } \\
\hline _Psychology \& attitude & _Style & _Voice effect & \\
\hline Eye contact & _Body gestures & _Effects of multimedia aids & \\
\hline \multicolumn{4}{|l|}{ Question response } \\
\hline Question-answer strategi & & & \\
\hline
\end{tabular}

